\title{
Assessment of Play and Sedentary Behaviours Before and During the Covid-19 Pandemic in Children Aged 10-16 Years Old- A Pilot Study
}

\author{
Ashi Jain ${ }^{1}$, Priyanka Shirsath ${ }^{2}$ \\ ${ }^{1}$ B.P.Th from DPO's NETT College of Physiotherapy, Thane [W], Maharashtra, India. \\ ${ }^{2}$ Assistant Professor, DPO'S NETT College of Physiotherapy, Thane [W], Maharashtra, India.
}

Corresponding Author: Ashi Jain

\begin{abstract}
Aim: The aim of the study is to assess if there are any changes in the play, sedentary and mood behaviours of children aged between 10-16 years of age before and during the on-going covid-19 pandemic.

Background: Covid-19 pandemic led to closures of schools and play grounds, social distancing, quarantining, etc., impacting the lifestyle activities of children and adolescents across the entire day. This led to an increase in the sedentary behaviours and decreased physical activity in children having detrimental effects on cardiometabolic/psychosocial health. In this study we aim to see the impact on lifestyle, mood, movement and screen time of children aged 10-16 years old before and during the Covid-19 global pandemic using online self-administered survey.

Methodology: 100 online responses were collected from children as per inclusion criteria. Demographic data and consent was taken. The survey was divided into 2 parts 1) Lifestyle and Study behaviours of the child- having 6 questions based on health, study, sleep cycle and motivation of the child, etc. 2) Movement and Screen timing of the child- which included the hours and type of physical activity, screen time and school's participation which was responded by the parents/older children based on before and during the Covid-19 period. The 100 responses were statistically calculated.

Result: The study concludes that sedentary behaviours due to reduced physical activity and increased screen time including all gadgets have impacted the mood, diet, sleep, study of the child. This highlights the need for strategies to promote physical activity and reduce sedentary time in children during the current and potential future pandemics to prevent long-term health risks.
\end{abstract}

Keywords: Covid-19 pandemic, physical activity, sedentary behaviour, children, school.

\section{INTRODUCTION}

The COVID-19 pandemic in India is a world- wide pandemic caused by severe acute respiratory syndrome coronavirus 2 (SARS-CoV-2). The $1^{\text {st }}$ case of COVID-19 in India was reported on 30 January 2020. Currently, it has the largest number of confirmed cases in Asia. India has the second-highest number of covid-19 cases in the world (after US) with 29.3 million reported cases as of 12 June, 2021 and the $3^{\text {rd }}$-highest number of deaths caused by Covid -19 pandemic after the US and Brazil at 367,081 deaths. The vaccination programme began in India on 16 January 2021, and by April it was administering 3-4 million doses a day. India has authorised the Oxford-AstraZeneca vaccine (Covishield), Covaxin which is produced in India, Sputnik V, and the Moderna vaccine. The schools, sports grounds, theatres, parks have been shut since March, 2020 to till date. The closures of schools, along with social distancing, quarantining, levelled lockdowns, restricted use are impacting the lifestyle of children 
and adolescents across the 24 hours in a day for months altogether now. Evidence suggests that restrictions put socially $\mathrm{pr}$ personally needed to reduce the spread of COVID-19 have increased engagement in sedentary behaviours, interrupted sleep patterns and decreased opportunities for children/adolescents to engage in PA thus affecting their academic performance too. This is detrimental and can lead to longterm cardiometabolic and psychological health outcomes in children and adolescents. [1]

'Any type of bodily movement brought about by skeletal muscles which result in expenditure of energy' has been described as Physical Activity, and decreased levels of sedentary time spent in front of screens /monitors/phones have been seen to improve physical, psychosocial, emotional and mental health amongst children and adolescents. For a healthy lifestyle, the WHO along with other authors have recommended moderate-to-vigorous of PA, 1 hour daily for children and adolescents with low recreational screen time (ST) Although, there is no ST recommendations for children and adolescents, several experts believe that no $>2$ hours of recreational ST for youth should be advocated. ${ }^{[2]}$

Sedentary behaviour (SB), can be described as any kind waking behaviour having expenditure of energy of $\leq 1.5$ METs, while in postures such as sitting, reclining/ lying ${ }^{[3]}$. SB is an independent and deadly in the long term risk factor for cardiometabolic disease in adults, children and adolescents. A recommendation of $\leq 2 \mathrm{~h}$ of recreational screen time for 5-17-year-olds per day is advocated by WHO. Sleep disturbances can have a serious effect on concentration, attention span, emotional health, social health, immune function, and academic performance and many other factors. For 517-year-olds, 9-11 h of uninterrupted sleep is recommended. Insufficient sleep increases cardiometabolic disease risk, obesity risk and also results in anxiety or mood swings, which may be supported by poor mental health during the COVID-19 pandemic. ${ }^{[1]}$ Lockdown is said to be as any measure adopted to contain or limit the pandemic by employing social distancing measures. School closures and online classes or home schooling was the measure adopted in almost all cases during the first wave of the COVID-19 for both primary and secondary schools in all types of studies and is still going on as a precautionary measure. ${ }^{[4]}$ Since the onset of the COVID19 pandemic, there are limited data investigating changes and impacts on children and adolescents' physical activity levels. There is lack of evidence for the influence of the COVD-19 pandemic on lifestyle behaviours in young adults, particularly from Mumbai, India. Thus, this study is aimed at investigating the PA levels, time spent in SB, and sleep in Mumbai's young adults during the COVID19 pandemic and also the changes in these lifestyle behaviours after the COVID-19 outbreak. So that the concerned education rules and regulation bodies, schools, parents understand the gravity of Covid-19 pandemic influence in children and its effect on their growth both physically and mentally. Hence there is the need of study.

\section{MATERIALS AND METHOD}

Materials: Google Forms, Mobile Phones, Wi-Fi or Mobile Data.

Sample Design- A Pilot Study

Sample Size: 100

Sample population: Children aged 10-16 years old, both genders included.

Sampling: Convenient Sampling

Type of study - Cross-sectional Observational Study

Duration of study - 1 year

Place of study - South Mumbai (Metropolitan City), India.

\section{Selection Criteria:}

\section{INCLUSION CRITERIA:}

- Children aged 10- 16 years old- both gender included.

- Children who are doing online studying in any school in the metropolitan city. 
- Children who have lived in metropolitan city throughout the globally affecting covid-19 pandemic.

- Children and parents willing to participate in the study.

- Children aware with the use of electronic gadgets

\section{EXCLUSION CRITERIA:}

- Children who suffer from any neurological or musculoskeletal problems.

- Children who suffer from any psychological problems.

- Children whose parents are unaware of the use of Google survey forms.

- Children who do not attend online school regularly.

\section{PROCEDURE}

Ethical clearance from ethical committee was taken. Selection of the subjects was done on the basis of the inclusion and exclusion criteria. The aim, need of study and procedure was explained to the subjects and their parents/guardians in their understood language. Consent from parents/guardians having children who are younger than or of 13 years old and Selfadministered consent from adolescents who are above the age of 13 years was taken via the Google form before the questionnaire was answered. Children were instructed to fill out the questionnaire by themselves in case of older than 13 years old. If the child was younger than 13 years old, the parent and the child were instructed to complete the questionnaire together. Children with ongoing- online studies throughout the covid-19 pandemic were included in the study. A minimum of 6 hours of online schooling was expected. Students / parents were made to that an online Google form survey that included a self -administered questionnaire about their physical activity, sleep, study and sedentary behaviours. The baseline survey took approximately 15 mins to complete and similar questions were divided into before and during the covid-19 pandemic sections. Participants had the option to complete it either on their mobile phone, tablet, or desktop device. If a parent had more than one child between ages 10-16 years, they were asked to fill out the forms for both the children separately. Parents were asked to fill out the important personal details before filling out the questionnaire. Parents were explained to fill out the Google forms by selecting on the options given or writing short answers where asked. Google forms were obtained. Data was collected and analysed.

\begin{tabular}{l} 
SELF OR PARENTS/GUARDIANS ADMINISTERED SUBJECTIVE QUESTIONNAIRE via GOOGLE FORMS. \\
GOOGLE FORM FOR BEFORE THE COVID-19 PERIOD - PART 1 OF THE FORM \\
\begin{tabular}{|l|}
\hline A) LIFESTYLE AND STUDY BEHAVIORS OF THE CHILD BEFORE THE COVID-19 PANDEMIC. \\
\hline 1) CONSIDERING THE CHILD'S WEIGHT AND HEIGHT, HE/SHE FELL INTO WHICH CATEGORY BEFORE THE PANDEMIC? \\
\hline UNDER NORMAL \\
\hline NORMAL \\
\hline OBESE \\
\hline HIGHLY OBESE \\
\hline \\
2) WHAT KIND OF DIET WAS FOLLOWED BY YOUR CHILD BEFORE THE PANDEMIC? \\
\hline SOMEWHAT HEALTHY \\
\hline QUITE HEALTHY \\
\hline SOMEWHAT UNHEALTHY \\
\hline QUITE UNHEALTHY \\
\hline \\
\hline 3) HOW WAS YOUR CHILD'S SOCIAL BEHAVIOR BEFORE THE PANDEMIC? \\
\hline SOMEWHAT INTROVERT \\
\hline AMBIVERT \\
\hline SOMEWHAT EXTROVERT \\
\hline
\end{tabular} \\
\hline
\end{tabular}


Ashi Jain et.al. Assessment of play and sedentary behaviours before and during the COVID-19 pandemic in children aged 10-16 years old- a pilot study.

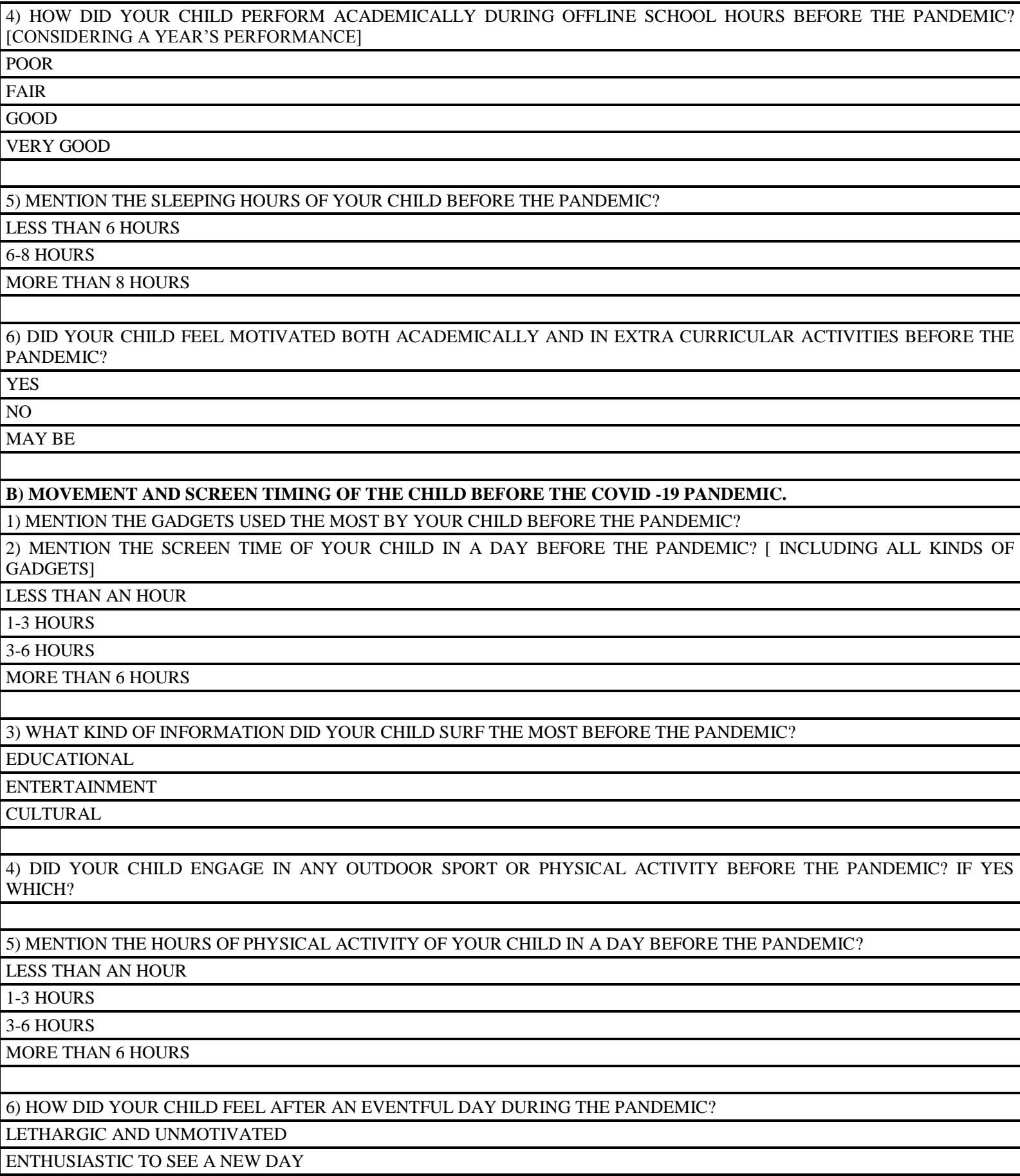

GOOGLE FORM FOR DURING THE COVID PERIOD - PART 2 OF THE FORM

C) LIFESTYLE AND STUDY BEHAVIORS OF THE CHILD DURING THE ONGOING COVID -19 PANDEMIC.

1) CONSIDERING THE CHILD'S WEIGHT AND HEIGHT, HE/SHE FELL INTO WHICH CATEGORY DURING THE PANDEMIC?

UNDER NORMAL

NORMAL

OBESE

HIGHLY OBESE

2) WHAT KIND OF DIET WAS CONSUMED BY YOUR CHILD DURING THE PANDEMIC?

SOMEWHAT HEALTHY

QUITE HEALTHY

SOMEWHAT UNHEALTHY

QUITE UNHEALTHY 
Ashi Jain et.al. Assessment of play and sedentary behaviours before and during the COVID-19 pandemic in children aged 10-16 years old- a pilot study.

3) HOW IS YOUR CHILD'S SOCIAL BEHAVIOR DURING THE PANDEMIC?

SOMEWHAT INTROVERT

AMBIVERT

SOMEWHAT EXTROVERT

4) HOW DID YOUR CHILD PERFORM ACADEMICALLY DURING OFFLINE SCHOOL HOURS DURING THE PANDEMIC? [CONSIDERING A YEAR'S PERFORMANCE]

POOR

FAIR

GOOD

VERY GOOD

5) MENTION THE SLEEPING HOURS OF YOUR CHILD DURING THE PANDEMIC?

LESS THAN 6 HOURS

6-8 HOURS

MORE THAN 8 HOURS

6) DID YOUR CHILD FEEL MOTIVATED BOTH ACADEMICALLY AND IN EXTRA CURRICULAR ACTIVITIES DURING THE PANDEMIC?

YES

NO

MAY BE

D) MOVEMENT AND SCREEN TIMING OF THE CHILD DURING THE COVID -19 PANDEMIC.

1)MENTION THE GADGETS USED THE MOST BY YOUR CHILD DURING THE PANDEMIC?

2) MENTION THE SCREEN TIME OF YOUR CHILD IN A DAY DURING THE PANDEMIC? [ INCLUDING ALL KINDS OF GADGETS]

LESS THAN AN HOUR

1-3 HOURS

3-6 HOURS

MORE THAN 6 HOURS

3) WHAT KIND OF INFORMATION DID YOUR CHILD SURF THE MOST DURING THE PANDEMIC?

EDUCATIONAL

ENTERTAINMENT

CULTURAL

4) DID YOUR CHILD ENGAGE IN ANY OUTDOOR SPORT OR PHYSICAL ACTIVITY DURING THE PANDEMIC? IF YES WHICH?

5) MENTION THE HOURS OF PHYSICAL ACTIVITY OF YOUR CHILD IN A DAY DURING THE PANDEMIC?

LESS THAN AN HOUR

1-3 HOURS

3-6 HOURS

MORE THAN 6 HOURS

6) HOW DID YOUR CHILD FEEL AFTER AN EVENTFUL DAY DURING THE PANDEMIC?

LETHARGIC AND UNMOTIVATED

ENTHUSIASTIC TO SEE A NEW DAY

\section{RESULTS}

Data analysis was done using descriptive stats using SPSS 21. Statistics of 100 responses were collected by mean and mode was used in questions where a repetitive response was found. After the collection of online filled Google forms, a

total of 100 forms of children aged 10- 16 years were analysed and the results were found after a written consent was taken. There were no drop outs in the study.

\begin{tabular}{|l|l|}
\hline NUMBER OF SUBJECTS & 100 \\
\hline AGES & $10-16$ YEARS \\
\hline MEAN & 13 YEARS \\
\hline SD & 2.1 \\
\hline
\end{tabular}


AGE GROUP - TABULAR FORMAT

\begin{tabular}{|l|l|l|}
\hline AGE IN YEARS & NO. OF RESPONDENTS & PERCENTAGE \\
\hline 10 YEARS & 24 respondents & $24 \%$ \\
\hline 11 YEARS & 5 respondents & $5 \%$ \\
\hline 12 YEARS & 19 respondents & $19 \%$ \\
\hline 13 YEARS & 10 respondents & $10 \%$ \\
\hline 14 YEARS & 22 respondents & $22 \%$ \\
\hline 15 YEARS & 10 respondents & $10 \%$ \\
\hline 16 YEARS & 10 respondents & $10 \%$ \\
\hline
\end{tabular}

LIFESTYLE AND STUDY BEHAVIORS OF THE CHILD BEFORE AND DURING THE COVID-19 PANDEMIC.

BMI CATEGORY OF THE CHILDREN BEFORE AND DURING THE PANDEMIC.

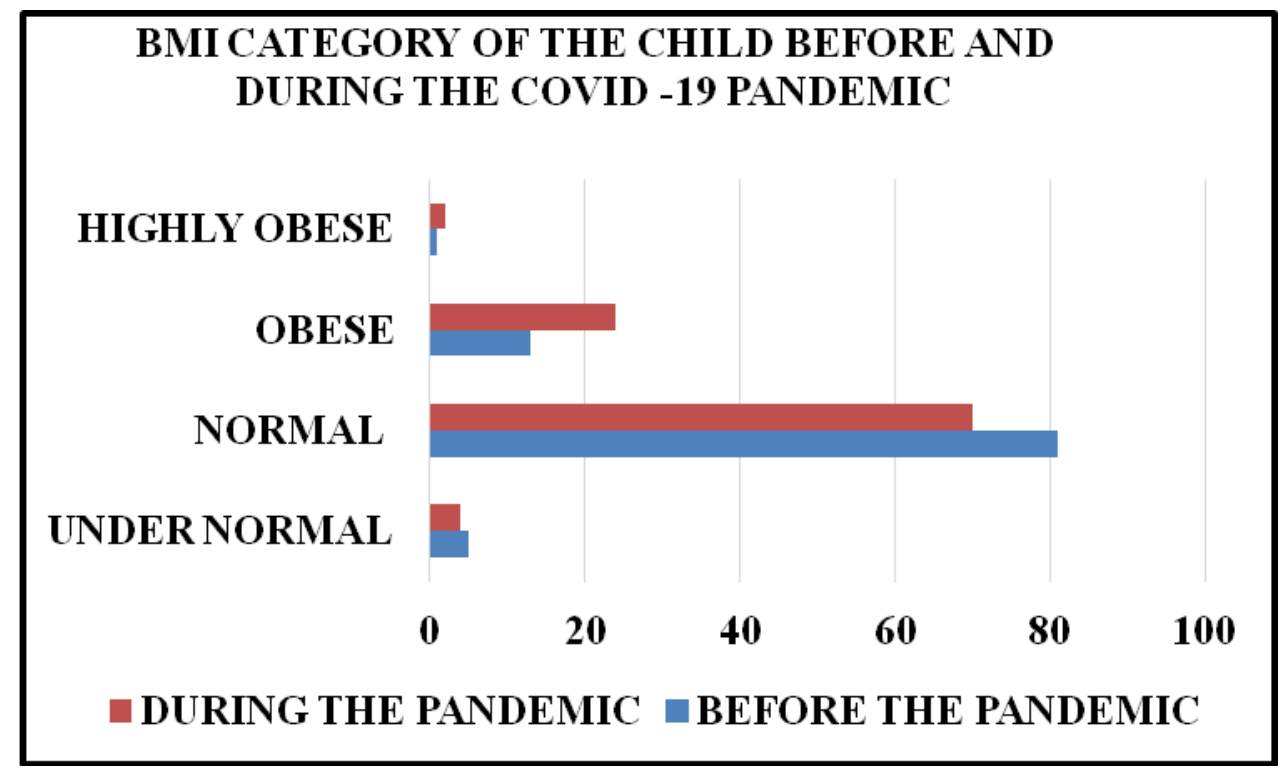

DIET FOLLOWED BY THE CHILD BEFORE AND DURING THE COVID-19 PANDEMIC.

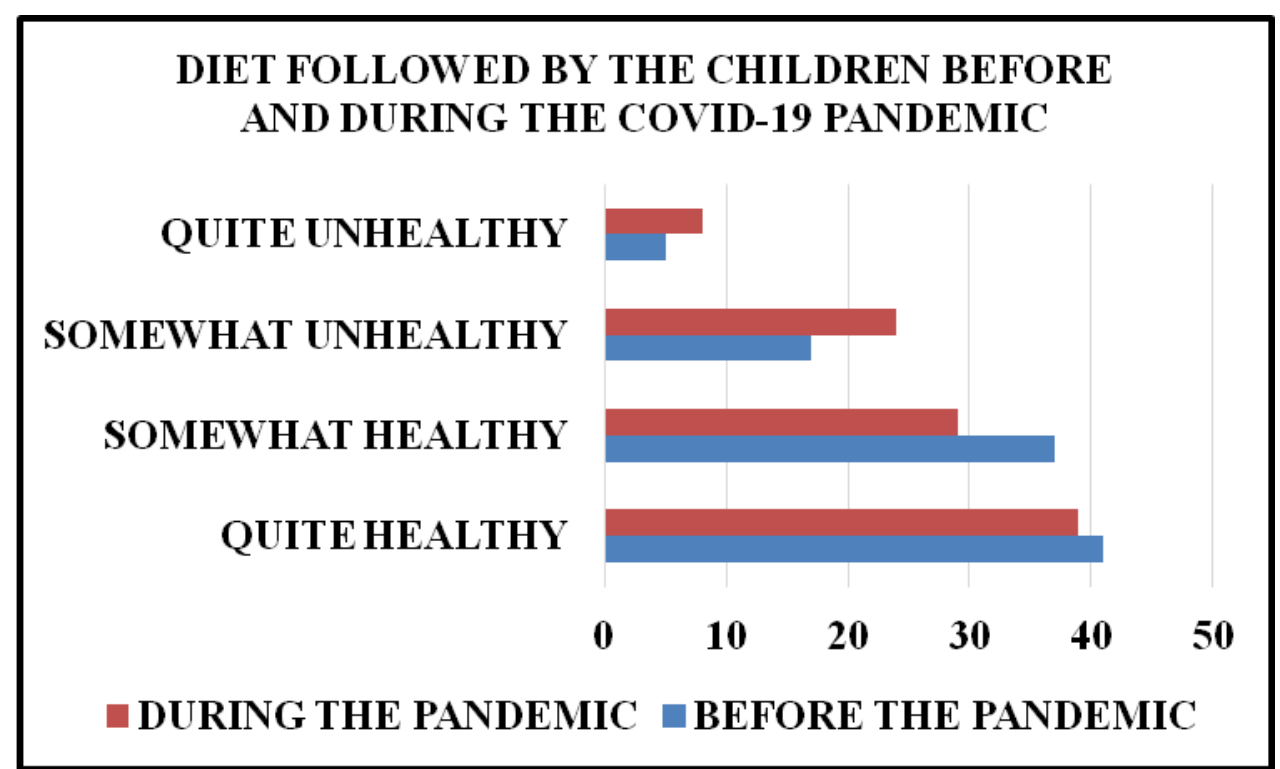


CHILD'S BEHAVIOR SOCIALLY SEEN BEFORE AND DURING THE COVID-19 PANDEMIC.

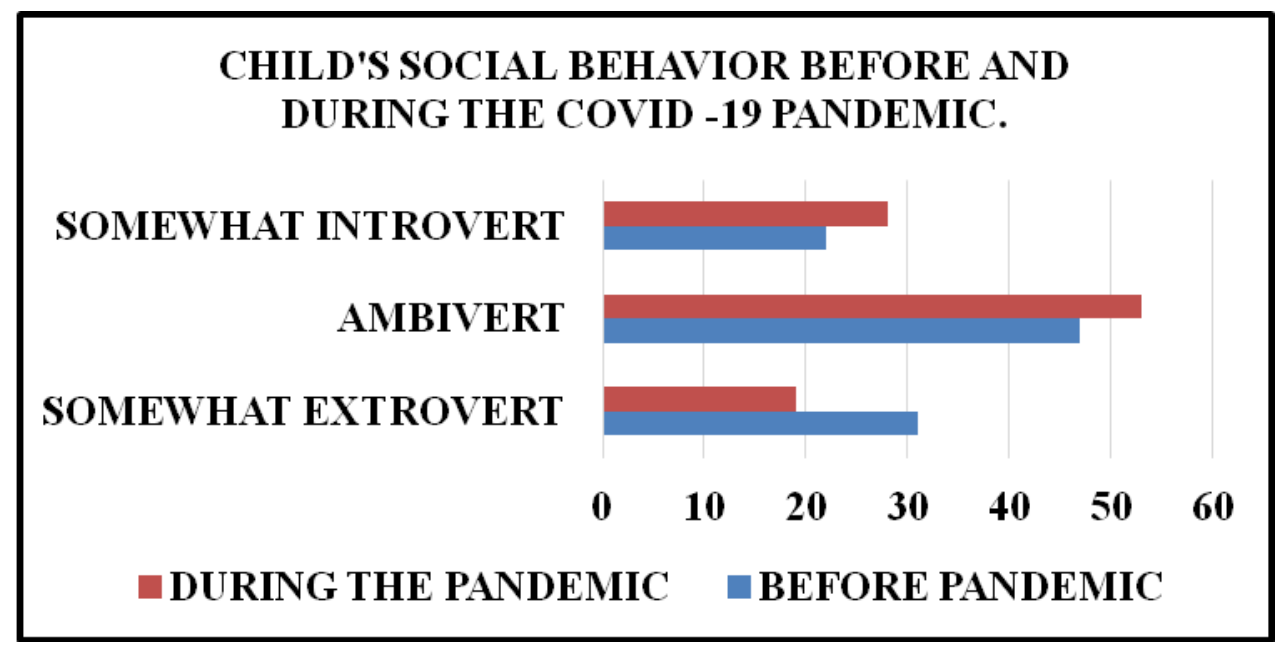

CHILD'S PERFORMANCE ACADEMICALLY BEFORE (OFFLINE) AND DURING (ONLINE) SCHOOL HOURS - CONSIDERING A YEAR'S PERFORMANCE

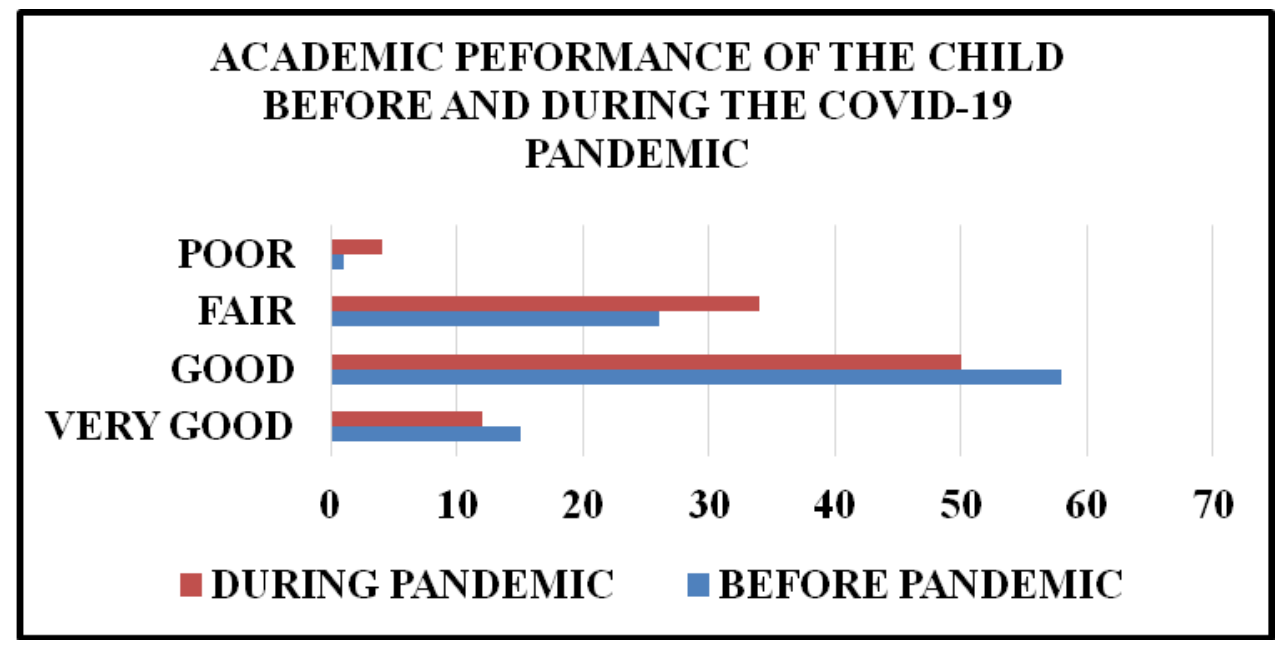

SLEEPING HOURS OF YOUR CHILD BEFORE AND DURING THE COVID-19 THE PANDEMIC.

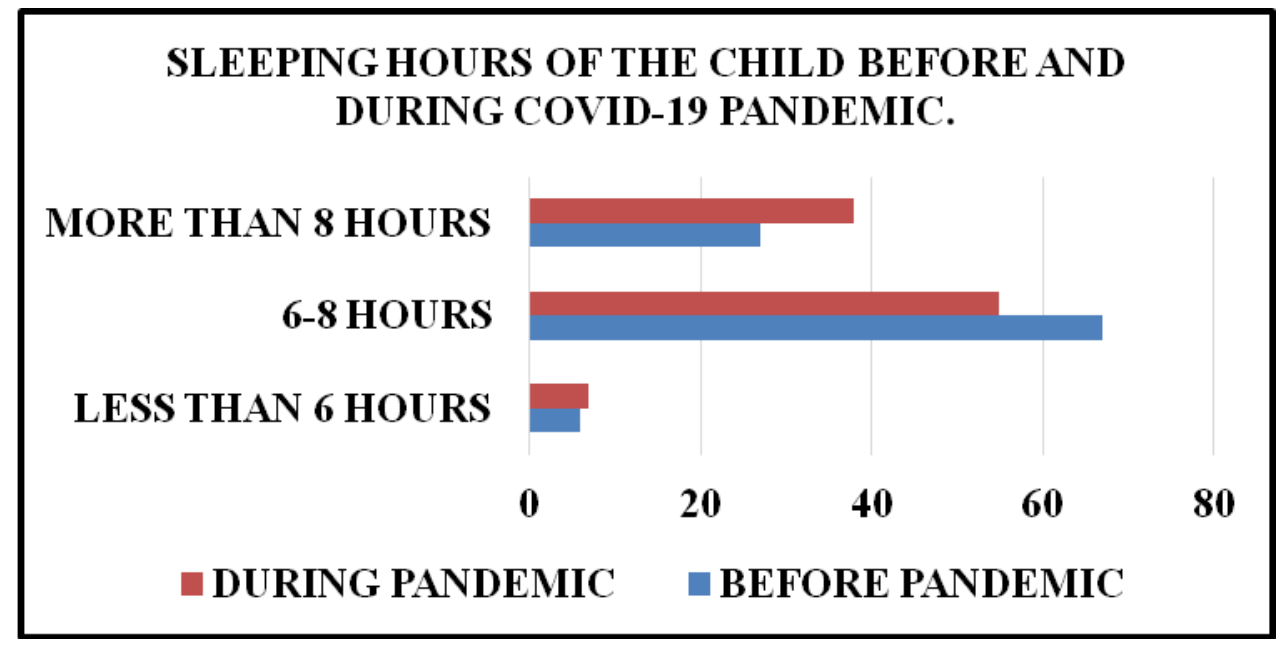


MOTIVATION OF THE CHILD BOTH ACADEMICALLY AND IN EXTRA CURRICULAR ACTIVITIES BEFORE AND DURING THE COVID-19 PANDEMIC.

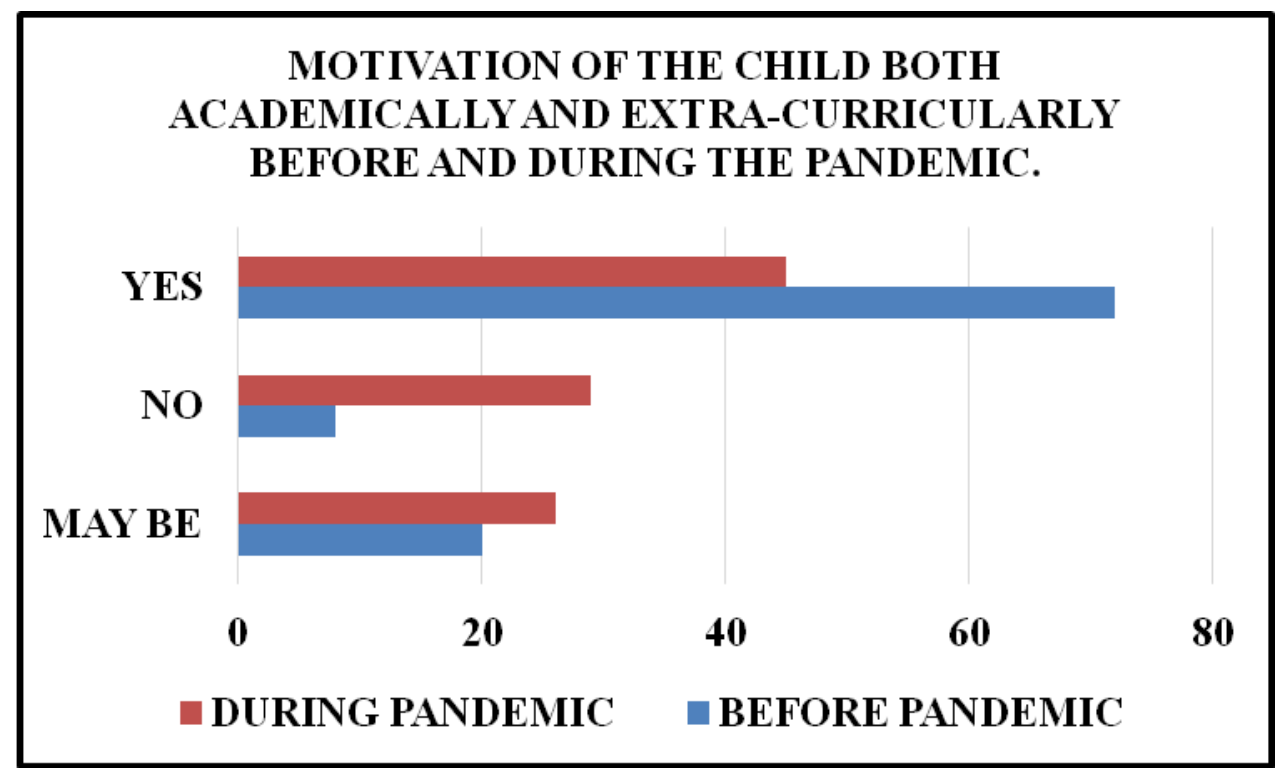

MOVEMENT AND SCREEN TIMING OF THE CHILD BEFORE AND DURING THE COVID -19 PANDEMIC.

- TYPES OF GADGETS USED BY THE CHILDREN

1. TELEVISION

2. LAPTOP/ DESKTOP

3. MOBILE PHONES

4. TABLETS/IPAD

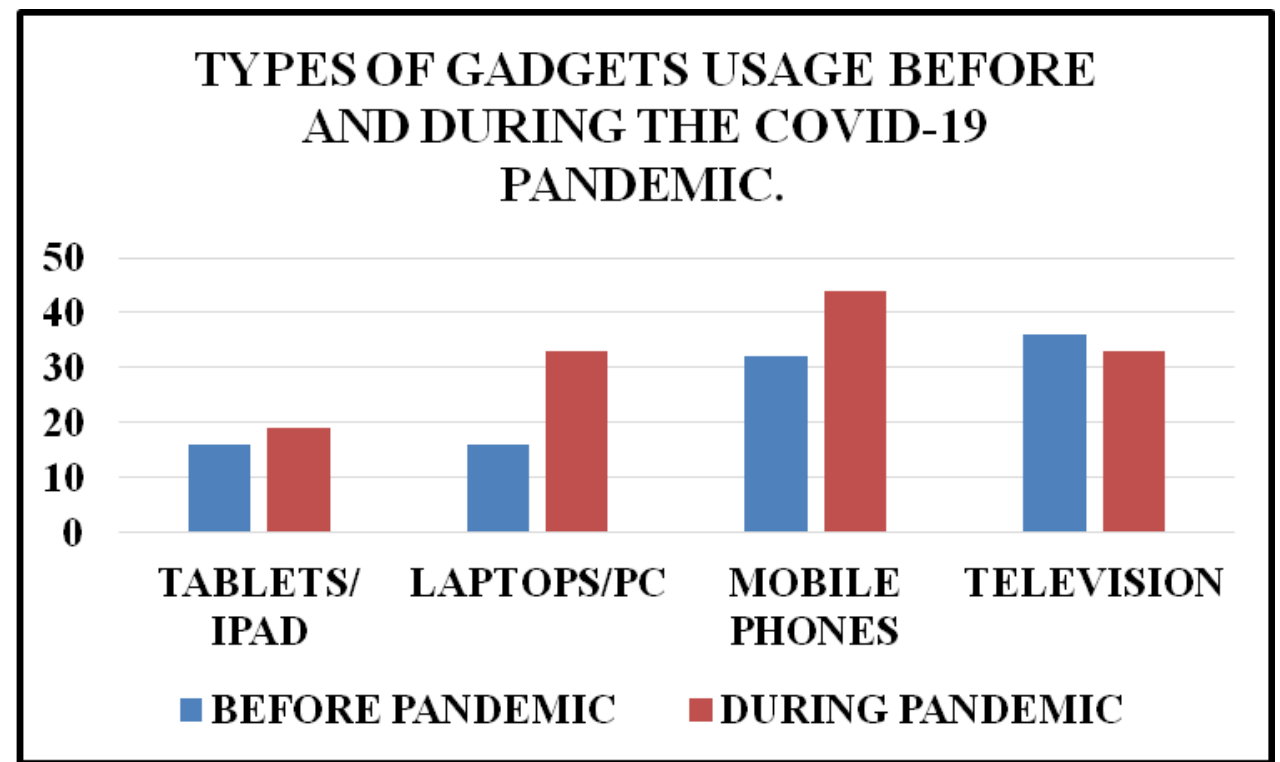


SCREEN TIME OF THE CHILD IN A DAY.

SCREEN TIME OF CHILDREN IN A DAY BEFORE

AND DURING THE COVID-19 PANDEMIC.

LESS THAN AN HOUR

1-3 HOURS

3-6 HOURS

MORE THAN 6 HOURS

$\begin{array}{llllllll}\mathbf{0} & \mathbf{1 0} & \mathbf{2 0} & \mathbf{3 0} & \mathbf{4 0} & \mathbf{5 0} & \mathbf{6 0} & \mathbf{7 0}\end{array}$

DURING PANDEMIC BEFORE PANDEMIC

KIND OF INFORMATION SURFED OR USED BY CHILDREN THE MOST BEFORE AND DURING THE COVID-19 PANDEMIC.

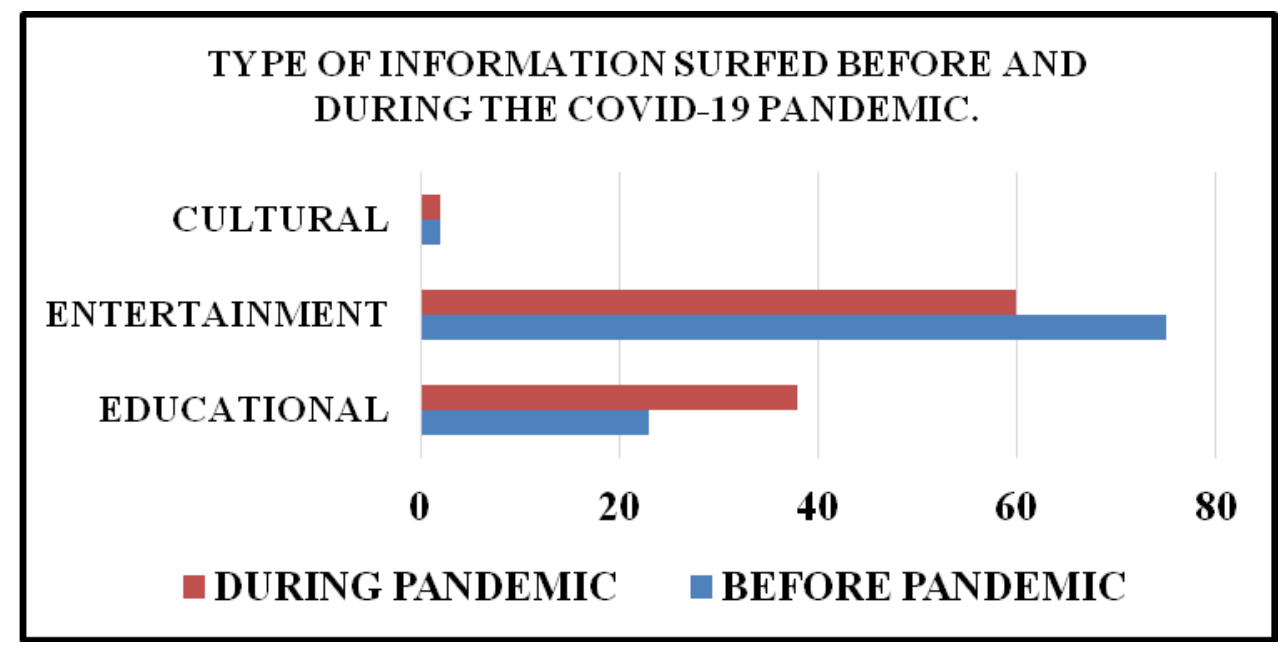

TYPES OF PHYSICAL ACTIVITY BEFORE AND DURING COVID-19 PANDEMIC.

\begin{tabular}{|c|c|c|c|}
\hline $\begin{array}{l}\text { SR. } \\
\text { NO. }\end{array}$ & $\begin{array}{l}\text { TYPE OF PHYSICAL } \\
\text { ACTIVITY }\end{array}$ & $\begin{array}{l}\text { PERCENTAGE OF } \\
\text { ENGAGED BEFORE }\end{array}$ & $\begin{array}{l}\text { PERCENTAGE OF } \\
\text { ENGAGED DURING }\end{array}$ \\
\hline 1 & FOOTBALL & 14 & 8 \\
\hline 2 & CRICKET & 14 & 10 \\
\hline 3 & BADMINTON & 14 & 14 \\
\hline 4 & FREE PLAY & 12 & 10 \\
\hline 5 & KARATE & 9 & $\mathbf{0}$ \\
\hline 6 & DANCE & 8 & 3 \\
\hline 7 & RUNNING & 6 & 5 \\
\hline 8 & CYCLING & 5 & 5 \\
\hline 9 & SWIMMING & 7 & $\mathbf{0}$ \\
\hline 10 & BASKET BALL & 2 & $\mathbf{0}$ \\
\hline 11 & HOCKEY & 1 & $\mathbf{0}$ \\
\hline 12 & SKATING & 1 & $\mathbf{0}$ \\
\hline 13 & GYNASTICS & 1 & $\mathbf{0}$ \\
\hline 14 & NONE AT ALL & 6 & 45 \\
\hline
\end{tabular}


HOURS OF PHYSICAL ACTIVITY DONE BY YOUR CHILD IN A DAY BEFORE AND DURING THE PANDEMIC.

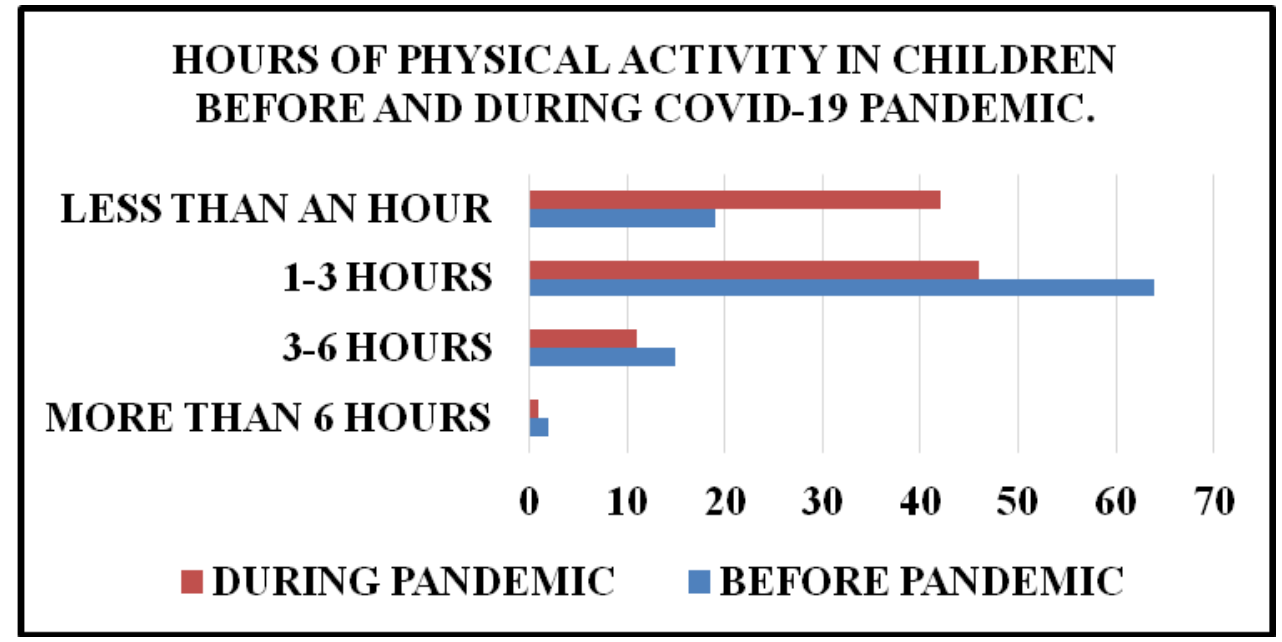

CHILDREN AFTER AT THE END OF A DAY BEFORE AND DURING THE COVID -19 PANDEMIC.

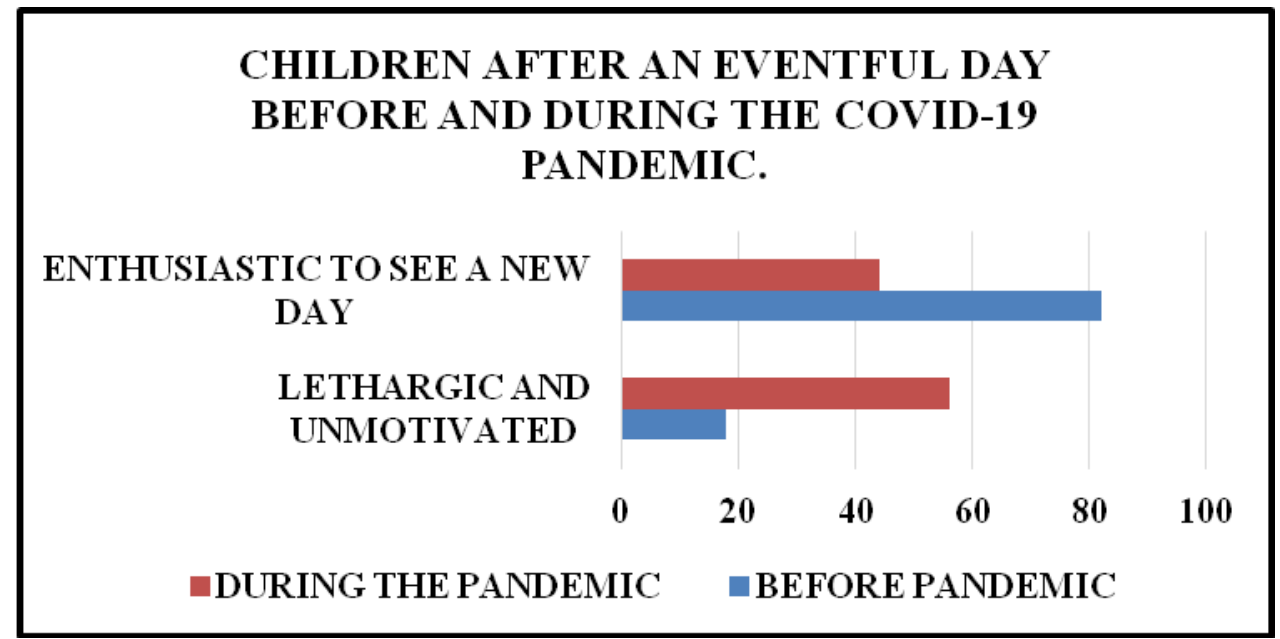

REPORT FOR SCHOOL'S INITIATIVE TO CONDUCT PHYSICAL ACTIVITIES ONLINE FOR CHILDREN DURING THE PANDEMIC.

F] DOES THE SCHOOL TAKE AN INITIATIVE TO CONDUCT PHYSICAL ACTIVITIES ONLINE? 100 responses
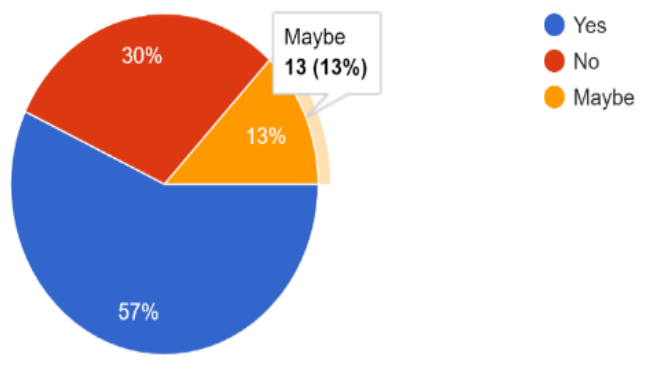
each, followed by free-play, karate and dance at $12 \%, 9 \%$ and $8 \%$ respectively with only $6 \%$ not being involved in any kind of activity. However, during the pandemic $45 \%$ of children demotivated into not doing any kind of activity. Mostly, badminton and free-play was preferred in the peri covid-19 period. The possible reasons for decline in football, cricket and badminton preferences is due to inability to go outdoor due to restrictions in using gardens, turfs, fields, etc. This was supported by the studies conducted in Germany and USA which concluded that although school/park closures and cancellations of team sports and activity classes were necessary steps to mitigate the spread of the virus and allow healthcare facilities to build capacity but they had appeared to have had a substantial impact on children's PA and SB levels- especially among 9-13years old. ${ }^{[}$

As per the results of this study a significant increase was seen in the screen time of children reaching up to $37 \%$ from 6 $\%$ (before pandemic). Children started to spend more time on the screen (more than 6 hours) due to online schooling, decreased outdoor activity, boredom. As per a study, TV usage increased by 21 minutes, use of gaming increased by 21.5 minutes, and usage of internet for recreational activities increased by 18.5 minutes, and the total amount of recreational ST increased by 1 hour and 2 minutes per day. A Spanish study found an increase in ST of one and a half hours in 3-5-year-olds and up to 2-3 hours amongst 13-16-year-olds per day and a significant increase of 36 minutes in sleep per day among the 13-16-year olds during strict COVID-19 confinement. An increment in daily recreational Screen time among 6- to 17-year-olds from 30 minutes to 1 hour was reported in a Chinese study. The numerically larger increase in ST with increasing age found by a German study that interviewed more than 8000 parents of 3-15 years old children during the lockdown concluded an increase of $38 \%$ in kindergarten to $72 \%$ in secondary education children. ${ }^{[8]}$ One study reported, $43 \%$ children spent more time on screens on weekdays $(34 \pm 105 \mathrm{~min} /$ day, $\mathrm{P}=<.01)$ during the COVID-19 pandemic. On average, school and study related screen time increased by $43 \pm 175 \mathrm{~min} /$ day $(\mathrm{P}=$ $.04)$. Screen time on weekend days did not change significantly. Chinese children reported an average increase of 30 hours/week, however, only $30.9 \%$ of the interviewed children reported more than 2 hours of screen time per day for leisure. ${ }^{[9]}$ A major drop was seen in the physical activity of children with more than $42 \%$ children engaging in less than 1 hour of physical activity in peri Covid -19 period. $64 \%$ children who engaged into 1-3 hours of PA in pre covid-19 pandemic declined to $46 \%$ during pandemic. A study indicates that the majority of Dutch children reported decreased levels of total PA during the COVID-19 pandemic compared to before, which was confirmed by Accelerometer. To support this study, $36 \%$ percent of US parents, $94 \%$ of South Korean parents and $42 \%$ of Dutch parents estimated that their children were less physically active during the COVID-19 pandemic compared to prior to the pandemic for various reasons. The data also indicated that compared to the preCOVID period, screen time increased by 1 hour per day and sedentary time by with 45 $\mathrm{min} / \mathrm{d}$, during the lockdown of spring 2020 globally as an average. ${ }^{[9]}$

Another study found out changes in total daily PA from 142.2 minutes pre to 167.8 minutes during the lockdown. In opposition, the study among 6- to 17-years old from Shanghai city concluded a change in total daily Physical activity from 1 hour and 17 minutes pre to 15 minutes during the lockdown in the pandemic. ${ }^{[8]}$

PA is related to the mood states of children and adolescents, and lower PA levels showed high scores in negative mood states. Higher levels of PA were related with better mood states and productivity in children and adolescents. ${ }^{[10]}$

This indicates that both physical activity and screen time are positively 
associated with the mood of the child which ultimately affects the academic as well as the extracurricular performance. Sleep cycle also was also seen to be positively associated with the physical activity, screen time and mood of the child. Our study also indicated that schools were taking an initiative to conduct recreational/ physical activities but not enough to impact a child's physical or mental health thus being of least use.

\section{Limitations:}

The study was conducted when India had already gone through two waves of the deadly corona virus pandemic and hence moderate to severe lockdown restrictions were seen in the various locations which impacted the reach to parents / children. Parents feared to let their children out and went through a lot of emotional and mental stress making them reluctant towards taking the study even though it was an online mode survey. Also, the baseline questionnaire could be subjected to recall-bias as PA and screen-time were questioned beforehand regarding the period before to the lockdown thus challenging the accuracy of it. Also, questions on physical activity and screen time might be difficult to interpret or answer when comparing before and during the covid-19 pandemic period, and parents might not have fully understood the concept thus, introducing some reporting error and biases cause most of the school-aged children were not under the eye of their parents' presence during school hours. Also, some parents with essential jobs - working out of the home and parents who were working full time at home during the COVID-19 period may not have an accurate representation of how much time their children were spending in each type of activity. The population size might not be enough to represent data for the entire young population hence further studies are required. A certain amount of hesitation was seen amongst parents to reveal the actual academic performance of their child, the changes in weight or even their mood changes which could have caused reporting errors.

\section{CONCLUSION}

PA levels in school-aged children decreased during the COVID-19 pandemic, while screen time increased and children were more sedentary in the peri Covid -19 pandemic period as compared to before. The study concludes that sedentary behaviours due to reduced physical activity and increased time on screen including all gadgets have impacted the mood, diet and sleep of the child thus affecting their academic performance.

\section{Clinical Implications:}

These findings highlight the need for strategies to promote PA and reduce sedentary time, including screen-time, in children during the current and potential future pandemics to prevent long-term health risks. Schools and families play major role in overcoming this menace and hence active participation is needed from both ends to boost a child's confidence during such unprecedented times. Further studies are required to confirm the same in different age groups, sexes or populations.

\section{Acknowledgement: None}

\section{Conflict of Interest: None}

\section{Source of Funding: None}

\section{Ethical Approval: Approved}

\section{REFERENCES}

1. Lauren C. Bates, Gabriel Zie, Kathleen Stanford, Justin B. Moore et al. COVID-19 Impact on Behaviours across the 24-Hour Day in Children and Adolescents: Physical Activity, Sedentary Behaviour, and Sleep. Children Journal .September 2020; 7(138) : 2-9.

2. Chen Zheng, Wendy Yajun Huang, Sinead Sheridan, Cindy Hui-Ping Sit et al. COVID19 Pandemic Brings a Sedentary Lifestyle in Young Adults: A Cross-Sectional and Longitudinal Study. International Journal of 
Environmental Research and Public Health. 2020; 17 (6035) : 1-3.

3. Schuch F, Bulzing R, Meyer J, LópezSánchez G. Moderate to vigorous physical activity and sedentary behavior changes in self-isolating adults during the COVID-19 pandemic in Brazil: a cross-sectional survey exploring correlates. Sport Sci Health Journal.2021 June 5 ; 1(9):2-4.

4. Luis Rajmil , Anders Hjern, Perran Boran,Geir Gunnlaugsson et al. Impact of lockdown and school closure on children's health and well-being during the first wave of COVID-19: a narrative review. BMJ Paediatrics Open. May 2021; $5: 1-3$.

5. Androniki Stavridou, Evangelia Kapsali, Eleni Panagouli, Athanasios Thirios et al. Obesity in Children and Adolescents during COVID-19 Pandemic. Children Journal. February 2021; 8 (135) : 1-3.

6. Rita Francisco, Marta Pedro1, Elisa Delvecchio, Jose Pedro Espada. Psychological Symptoms and Behavioural Changes in Children and Adolescents During the Early Phase of COVID-19 Quarantine in Three European Countries. Frontiers in Psychiatry. 2 December 2020 ; Volume 11 (570164) : 5-11.

7. Genevieve F. Dunton, Bridgette Do, Shirlene D. Wang. Early effects of the COVID-19 pandemic on physical activity and sedentary behaviour in children living in the U.S. BMC Public Health . $2020 ; 20$ (1351) : 1-3.

8. Steffen C. E. Schmidt, Bastian Anedda, Alexander Burchartz, Ana Eichsteller et al. Physical activity and screen time of children and adolescents before and during the COVID- 19 lockdown in Germany: a natural experiment. Scientific Reports. 2020; 10 (21780) :6-12.

9. Gabrielle ten Velde, Judith Lubrecht, Lisanne Arayess, Christiana van Loo et al. Physical activity behaviour and screen time in Dutch children during the COVID-19 pandemic: Pre-, during- and post-school closures. Pediatric Obesity. 2021;16(e12779) : 2-7.

10. Xinxin Zhang, Wenfei Zhu, Sifan Kang, Longkun Qiu et al. Association between Physical Activity and Mood States of Children and Adolescents in Social Isolation during the COVID-19 Epidemic. International Journal of Environmental Research and Public Health .October, 2020; 17(7666) : 2-12.

How to cite this article: Jain A, Shirsath P. Assessment of play and sedentary behaviours before and during the COVID-19 pandemic in children aged 10-16 years old- a pilot study. Int J Health Sci Res. 2021; 11(11): 23-36. DOI: https://doi.org/10.52403/ijhsr.20211104 